\title{
Gastrectomy and subsequent risk of oesophageal cancer in Milan
}

\author{
Carlo La Vecchia, Barbara D’Avanzo, Eva Negri, Silvia Franceschi, Peter Boyle
}

\begin{abstract}
Study objective - To analyse quantitatively the relationship between gastrectomy and oesophageal cancer risk.

Design - This was a case-control study, based on a structured questionnaire that included a problem-oriented medical history.

Setting - A network of hospitals in the Greater Milan area between 1984 and 1992.

Subjects - Subjects were 316 incident, histologically confirmed cases of oesophageal cancer ( 258 males and 58 females), and 1408 controls (1031 males, 377 females), admitted to hospital for acute, non-neoplastic, non-digestive tract conditions.

Measurements and main results - Relative risks (RR) and the corresponding 95\% confidence intervals (CI) adjusted for age and sex, plus area of residence, education, tobacco, and alcohol consumption. There was an association of borderline significance of oesophageal cancer with gastric ulcer $(R R=1 \cdot 6)$, but not with duodenal ulcer $(R R=0.9)$. Among cases, $25(7.9 \%)$ reported a history of gastrectomy, versus $29(2 \cdot 1 \%)$ of the controls. The corresponding multivariate $R R$ was $3 \cdot 8(95 \%$ CI $2 \cdot 0,7 \cdot 0)$. The RR of oesophageal cancer was significantly raised $(R R=3.6)$ within 20 years after gastrectomy, and the association seemed stronger with increasing time since gastrectomy $(R R=4 \cdot 2)$.

Conclusions - Since gastrectomy may cause gastric hypoacidity and favour oesophageal reflux, and hence oesophagitis, the results of this study, if confirmed, are of interest to a better understanding of the mechanisms of oesophageal carcinogenesis.
\end{abstract}

\section{( $\mathcal{F}$ Epidemiol Community Health 1994;48:310-312)}

Istituto di Biometria Statistica Medica, Università di Milano, 20133 Milan, Italy $\mathrm{C}$ La Vecchia

Centro di Riferimento Oncologico di Aviano, 33081 Aviano

(Pordenone), Italy

$S$ Franceschi

Istituto Europeo di Oncologia, 20144

Milan, Italy

P Boyle

Correspondence to

Dr La Vecchia.

Accepted for publication October 1993

Several studies have considered the impact of gastrectomy on the subsequent risk of cancer of the gastric stump. ${ }^{1-11}$ The overall epidemiological evidence indicates that there is no increased risk during the first 15 to 20 years after partial gastrectomy, but most studies have found increased gastric cancer rates after longer time intervals. The interpretation of these findings is, however, difficult, particularly since a limited and variable portion of the gastric epithelium is left.

Little information is available on the risk of other digestive neoplasms after gastrectomy, and in particular of oesophageal cancer. In a cohort of over 5000 patients followed for more than 25 years in England ${ }^{12}$ six deaths from oesophageal cancer were observed versus 2.8 expected, corresponding to a (statistically significant) standardised mortality ratio of $2 \cdot 3$. Some excess risk was also reported from similar investigations conducted in The Netherlands ${ }^{13}$ and Denmark, ${ }^{9}$ but not from a Norwegian cohort. $^{10}$ In those studies, the absolute numbers of cases were extremely low, however, and none of the findings was significant.

To provide further quantitative information on the possible relationship between gastrectomy and subsequent oesophageal cancer risk, we analysed data from a case-control study conducted in northern Italy.

\section{Subjects and methods}

The data were derived from a continuing study of upper digestive and respiratory tract neoplasms, conducted in a network of hospitals, including major teaching and general hospitals, in the Greater Milan area, whose general design has already been described. ${ }^{14}$

Briefly, between January 1984 and December 1992, 316 incident, histologically confirmed cases of oesophageal cancer ( 258 males and 58 females, median age 59 years, range 28 to 74) were interviewed. No information was collected on the exact site of origin (upper, median, or lower third) of the neoplasm.

The comparison group included 1408 controls (1031 males, 377 females, median age 51 years, range 26 to 74 ) admitted to the same network of hospitals for a wide spectrum of acute, non-neoplastic, non-digestive-tract conditions (35\% traumas, $17 \%$ other orthopaedic conditions, $32 \%$ acute surgical diseases, $16 \%$ other miscellaneous disorders). Less than $4 \%$ of subjects identified (cases and controls) refused to be interviewed. The catchment area of cases and controls was comparable: $85 \%$ of cases and $88 \%$ of controls resided in the same region, Lombardy, and over $90 \%$ of both cases and controls came from northern Italy.

A structured questionnaire was used to obtain information on sociodemographic factors, personal characteristics, and habits, including tobacco and alcohol consumption, frequency of intake of a few selected indicator foods, and a problem-oriented medical history. Age at first diagnosis was specifically elicited for 14 selected diseases or interventions, including gastric ulcer, duodenal ulcer, and gastrectomy.

Data analysis was based on standard statistical methods for case-control studies, ${ }^{15}$ includ- 
ing age- (in quinquennia) and sex-adjusted odds ratios as estimations of relative risks (RR) and the corresponding $95 \%$ confidence intervals $(\mathrm{CI})$, and estimates from multiple logistic regression models. Included in the regression equations were terms for age, sex, area of residence, education, tobacco, and alcohol consumption.

\section{Results}

The distribution of oesophageal cancer cases and the comparison group according to sex, age group, education, and tobacco and alcohol consumption is given in table 1 . Cases were significantly less educated (RR for $\geqslant 12 v<7$ years of education $=0.6,95 \%$ CI $0.4,0.9)$ and were more frequently smokers $(R R=4 \cdot 2,95 \%$ CI $1 \cdot 8,6 \cdot 2)$ and heavy drinkers $(\mathrm{RR}=3 \cdot 8$, $95 \%$ CI $2 \cdot 4,6 \cdot 1$ for $\geqslant 4$ drinks per day).

Table 1 Distribution of 316 cases of oesophageal cancer and 1408 controls according to sex, age, and selected variables. Milan, Italy, 1984-92

\begin{tabular}{|c|c|c|}
\hline & Oesophageal cancer & Controls \\
\hline & No $(\%)$ & No $(\%)$ \\
\hline $\begin{array}{l}\text { Sex: } \\
\text { Men } \\
\text { Women }\end{array}$ & $\begin{array}{r}258(81 \cdot 6) \\
58(18 \cdot 4)\end{array}$ & $\begin{array}{r}1031(73 \cdot 2) \\
377(26 \cdot 8)\end{array}$ \\
\hline $\begin{array}{l}\text { Age group: } \\
<45 \\
45-54 \\
55-64 \\
65-74\end{array}$ & $\begin{array}{c}19(6 \cdot 0) \\
73(23 \cdot 1) \\
146(46 \cdot 2) \\
78(24 \cdot 7)\end{array}$ & $\begin{array}{l}264(18 \cdot 8) \\
382(27 \cdot 1) \\
459(32 \cdot 6) \\
303(21 \cdot 5)\end{array}$ \\
\hline $\begin{array}{l}\text { Education (y): } \\
\quad<7 \\
7-11 \\
\geqslant 12 \\
\text { Unknown }\end{array}$ & $\begin{array}{r}211(66 \cdot 8) \\
60(19 \cdot 0) \\
43(13 \cdot 6) \\
2(0 \cdot 6)\end{array}$ & $\begin{array}{c}669(47 \cdot 5) \\
414(29 \cdot 4) \\
317(22 \cdot 5) \\
8(0 \cdot 6)\end{array}$ \\
\hline $\begin{array}{l}\text { Tobacco smoking: } \\
\text { Never smokers } \\
\text { Ex-smokers } \\
\text { Current smokers }\end{array}$ & $\begin{array}{r}46(14 \cdot 6) \\
65(20 \cdot 6) \\
205(64 \cdot 9)\end{array}$ & $\begin{array}{l}526(37 \cdot 4) \\
295(21 \cdot 0) \\
587(41 \cdot 7)\end{array}$ \\
\hline $\begin{array}{l}\text { Alcohol drinking (d) } \\
\text { Non-drinkers } \\
<4 \\
\geqslant 4\end{array}$ & $\begin{array}{r}40(12 \cdot 7) \\
71(22 \cdot 4) \\
205(64 \cdot 9)\end{array}$ & $\begin{array}{l}283(20 \cdot 1) \\
628(44 \cdot 6) \\
497(35 \cdot 3)\end{array}$ \\
\hline
\end{tabular}

Table 2 Distribution of 316 cases of oesophageal cancer and 1408 controls according to a history of gastric and duodenal ulcer. Milan, Italy, 1984-92

\begin{tabular}{|c|c|c|c|c|}
\hline \multirow[b]{2}{*}{ Disease } & \multirow{2}{*}{$\begin{array}{l}\text { Oesophageal } \\
\text { cancer }\end{array}$} & \multirow[b]{2}{*}{ Controls } & \multicolumn{2}{|c|}{ Relative risk estimates $(95 \% \mathrm{CI})$} \\
\hline & & & $M-H^{*}$ & $M L R^{\dagger}$ \\
\hline $\begin{array}{l}\text { Gastric ulcer: } \\
\text { No } \\
\text { Yes }\end{array}$ & $\begin{array}{r}293 \\
23\end{array}$ & $\begin{array}{r}1348 \\
60\end{array}$ & $\begin{array}{l}1 \ddagger \\
1 \cdot 7(1 \cdot 0,2 \cdot 7)\end{array}$ & $\begin{array}{l}1 \ddagger \\
1.6(0 \cdot 9,2 \cdot 7)\end{array}$ \\
\hline $\begin{array}{l}\text { Duodenal ulcer: } \\
\text { No } \\
\text { Yes }\end{array}$ & $\begin{array}{r}289 \\
27\end{array}$ & $\begin{array}{r}1295 \\
113\end{array}$ & $\begin{array}{l}1+ \\
1 \cdot 0(0 \cdot 7,1 \cdot 6)\end{array}$ & $\begin{array}{l}1 \ddagger \\
0.9(0.6,1 \cdot 5)\end{array}$ \\
\hline
\end{tabular}

* Mantel-Haenszel estimates adjusted for quinquennia of age and sex.

† Estimates from multiple logistic regression equations including terms for age, sex, area of residence, education, and smoking and alcohol consumption.

$\ddagger$ Reference category

Table 3 Distribution of 316 cases of oesophageal cancer and 1408 controls according to history of gastrectomy and time since gastrectomy. Milan, Italy, 1984-92

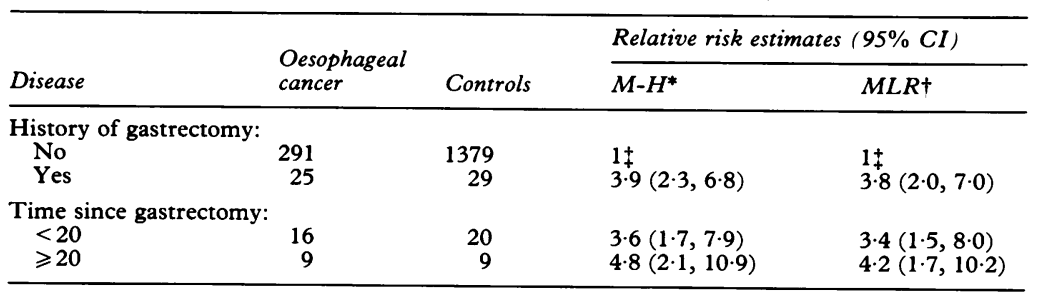

* Mantel-Haenszel estimates adjusted for quinquennia of age and sex.

† Estimates from multiple logistic regression equations including terms for age, sex, area of residence, education, and smoking and alcohol consumption

$\ddagger$ Reference category.
The history of gastric and duodenal ulcer is considered in table 2. Gastric ulcer was more frequently reported by oesophageal cancer cases $(7.3 v 4.2 \%$, corresponding to a multivariate $R R$ of 1.6 ). In contrast, no difference emerged for history of duodenal ulcer, reported by $8.5 \%$ of cases $v 8.0 \%$ of controls $(\mathrm{RR}=0.9)$.

The relationship between gastrectomy and oesophageal cancer is considered in table 3. Among cases, $25(7.9 \%)$ reported a history of gastrectomy $v 29(2 \cdot 1 \%)$ of the controls. Gastrectomy was more frequent in men $(8.3 \%$ of cases, $2.5 \%$ of controls) than in women $(3.4 \%$ of cases, $1.3 \%$ of controls), and of similar frequency in various age groups over age 50, whereas its prevalence declined steadily in younger groups. The overall RR for gastrectomy was $3.9(95 \% \mathrm{CI}, 2 \cdot 3,6 \cdot 8)$ after adjustment for age and sex only, and $3.8(95 \% \mathrm{CI}$ $2.0,7 \cdot 0$ ) after further allowance for area of residence, education, and smoking and alcohol consumption. The relative risk was similar for men $(\mathrm{RR}=4 \cdot 1,95 \% \mathrm{CI} 2 \cdot 3,7 \cdot 1)$ and women ( $R R=2 \cdot 7,95 \%$ CI $0.5,13 \cdot 2)$. The $R R$ of oesophageal cancer was significantly raised $(R R=3 \cdot 6)$ within 20 years since gastrectomy and, if anything, the association seemed stronger the longer the time since gastrectomy $(R R=4 \cdot 8)$. These risk estimates were not materially influenced by allowance for a number of potential confounding factors, using multiple logistic regression $(R R=3.4$ less than 20 years, and $4 \cdot 2$ since 20 or more years since gastretomy).

Information was also collected on medical treatment of peptic ulcer with $\mathrm{H}_{2}$ receptor antagonists (cimetidine and ranitidine). This was reported by seven cases and 76 controls, corresponding to an RR of $0.4(95 \% \mathrm{CI} 0.2$, $1 \cdot 0)$.

\section{Discussion}

The findings of this case-control investigation suggest that the risk of oesophageal carcinoma is increased in subjects who have undergone gastrectomy for benign conditions. The increased risk was consistent across strata of age and sex, was even present 20 or more years after gastrectomy, and was not explained through similarity of risk factors of gastroduodenal ulcer and oesophageal cancer, including alcohol and tobacco consumption. ${ }^{16}$

These findings are consistent with the results of three published cohort studies, ${ }^{91213}$ although the point estimates tend to be higher in the present dataset, and no association was observed in another cohort investigation. ${ }^{10}$ Still, the lower confidence limit of approximately 2 in the present study is compatible with previously published data. Thus, the present study offers further quantitative information on the possible relationship between gastrectomy and subsequent oesophageal cancer risk, but, on epidemiological grounds, the issue remains open to discussion.

On pathogenic grounds, however, the relationship has plausible correlates, since gastrectomy may cause gastric hypoacidity and favour 
oesophageal reflux and hence oesophagitis and other epithelial changes that are known precursors of oesophageal carcinoma. ${ }^{17-19}$ Thus, the persistence of the increased risk for a long time after gastrectomy, and its possible increase with increasing time, give additional support to the presence of a real association.

The present study has several limitations, including the absence of information on the type of gastric resection performed, since patients treated with Bilroth II operation may be more exposed to bile acid reflux. More important, perhaps, is the absence of data on the exact site of origin of the oesophageal neoplasm, since the lower third should be more exposed to potential carcinogens from gastric reflux and hence at specifically higher risk after gastrectomy.

The absence of association and interaction with medical treatment of peptic ulcer with $\mathrm{H}_{2}$ receptor antagonists is also of interest, and should be related to the pharmacokinetics of these drugs, which cause intermittent inhibition of the secretion of gastric acid. ${ }^{20}$

Other potential limitations of the casecontrol design include information bias, since recall of past surgery may be more accurate in cases. Gastrectomy is a major operation, however, and its recall should be reasonably accurate. The hospital-based setting should also improve the comparability of recall by cases and controls, ${ }^{21}$ and hence reduce this potential source of bias. Furthermore, cases and controls came from comparable catchment areas, the response rate was practically complete, and all digestive tract diseases or any conditions potentially related to established or suspected risk factors for oesophageal cancer were explicitly excluded from the comparison group. With reference to confounding, the results were not materially modified after allowance for major identified potential distorting factors.

In conclusion, the suggestion of increased oesophageal cancer risk after gastrectomy that emerges from this study, if confirmed by other investigations, may be of interest to a better understanding of some of the pathogenic mechanisms of oesophageal carcinogenesis. Even if real, however, this association would have limited public health implications, in view of the substantial decline in gastrectomy for the treatment of gastroduodenal ulcer since the introduction of effective medical treatment in the late 1970 s. $^{22}$
This work was conducted within the framework of the CNR (Italian National Research Council) applied projects "Clinical Applications of Oncological Research" (Contracts no 92.02384.PF39, and 92.02206.PF39) and "Prevention and no 92.02384.PF39, and 92.02206.PF39) and "Prevention and with the contributions of the Italian Association for Cancer Research, the Italian League Against Tumours, Milan, and Mrs A Marchegiano Borgomainerio. The authors wish to thank Mrs Judy Baggott, Mrs M Paola Bonifacino, and the GA Pfeiffer Memorial Library staff for editorial assistance.

1 Stahlsberg H, Taksdal S. Stomach cancer following gastric surgery for benign conditions. Lancet $1971 ;$ ii:1175-7.

2 McLean Ross AH, Smith MA, Anderson JR, Small WP Late mortality after surgery for peptic ulcer. $N$ Engl $\dot{f}$ Med 1982;307:519-22.

3 Caygill CPJ, Hill MJ, Kirkham JS, Northfield TC. Mortality from gastric cancer following gastric surgery for peptic ulcer. Lancet 1986;i:929-31.

4 Viste A, Bjørnestad E, Opheim P, et al. Risk of carcinoma following gastric operations for benign disease. A historical cohort study of 3470 patients. Lancet 1986;ii:502-5.

cal cohort study of 3470 patients. Lancet 1986;ii:502-5.
5 Tokudome S, Kono S, Ikeda M, et al. A prospective study on primary gastric stump cancer following partial gastrectomy for benign gastroduodenal diseases. Cancer Res 1984;44:2208-12.

6 Lundegardh G, Adami H-O, Helmick C, et al. Stomach cancer after partial gastrectomy for benign ulcer disease. $N$ Engl f Med 1988;319:195-200.

7 Arnthorsson G, Tulinius H, Egilsson V, Sigvaldason H, Magnusson B, Thorarinsson H. Gastric cancer after gastrectomy. Int $\mathcal{F}$ Cancer 1988;42:365-7.

8 Tersmette AC, Goodman SN, Offerhaus GJA, et al. Multivariate analysis of the risk of stomach cancer after ulcer surgery in an Amsterdam cohort of postgastrectomy pargery in an Amsterdam cohort of post

9 Møller H, Toftgaard C. Cancer occurrence in a cohort of patients surgically treated for peptic ulcer. Gut patients surgical

10 Eide TJ, Viste A, Andersen A, Søreide O. The risk of cancer at all sites following gastric operation for benign disease. A cohort study of 4,224 patients. Int $\mathcal{f}$ Cancer 1991;48:333-9.

11 La Vecchia C, Negri E, D'Avanzo B, Møller H, Franceschi $S$. Partial gastrectomy and subsequent gastric cancer risk. f Epidemiol Community Health 1992;46:12-4

12 Caygill CPJ, Hill MJ, Hall CN, Kirkham JS, Northfield TC. Increased risk of cancer at multiple sites after gastric surgery for peptic ulcer. Gut 1987;28:924-8.

13 Tersmette AC, Offerhaus GJA, Giardiello FM, Tersmette KWF, Vandenbroucke JP, Tytgat GNJ. Occurrence of non-gastric cancer in the digestive tract after remote non-gastric cancer in the digestive tract after remote partial gastrectomy: Anal

14 Decarli A, Liati P, Negri E, Franceschi S, La Vecchia C. Vitamin $A$ and other dietary factors in the etiology of osephageal cancer. Nutr Cancer 1987;10:29-37.

15 Breslow NE, Day NE. Statistical methods in cancer research. Vol I. The analysis of case-control studies. Lyon: IARC Sci Publ, 1980;no 32.

16 Franceschi S, Talamini R, Barra S, et al. Smoking and drinking in relation to cancers of the oral cavity, pharynx, larynx, and esophagus in Northern Italy. Cancer Res 1990;50:6502-7.

17 Reed PI, Smith PL, Haines K, House FR, Walters CL. Gastric juice $\mathrm{N}$-nitrosamines in health and gastroduodenal disease. Lancet 1981;ii:550-2.

18 Kuylenstierna R, Munck-Wikland E. Esophagitis and cancer of the esophagus. Cancer 1985;56:837-9.

19 Jaskiewicz K, Louwrens HD, Van Wyk MJ, Woodroof CL. Oesophageal carcinoma. Anticancer Res 1989;9:1191-6.

20 Feldman F, Burton ME. Histamine ${ }_{2}$-receptor antagonists. Standard therapy for acid-peptic diseases (First of two parts). $N$ Engl f Med 1990;323:1672-80.

21 Kelly JP, Rosenberg L, Kaufman DW, Shapiro S. Reliability of personal interview data in a hospital based casecontrol study. Am ₹ Epidemiol 1990;131:79-90.

22 La Vecchia C, Lucchini F, Negri E, Reggi V, Levi F. The impact of therapeutic improvements in reducing peptic ulcer mortality in Europe. Int $\mathcal{f}$ Epidemiol 1993;22:96106. 